\title{
Introduction to the special issue on adaptive flood risk management
}

\author{
Paul O’Hare' $^{1}$ Gina Cavan' ${ }^{1}$ Walter Leal Filho'
}

Received: 8 April 2016/Accepted: 13 April 2016/Published online: 21 April 2016

(C) Springer Science+Business Media Dordrecht 2016

Societal adaptation to extreme weather events is now widely acknowledged to be a political and practical imperative. The widely recognised challenges of urban densification, a changing climate and associated intensifying weather extremes, inadequate infrastructures, and altered responsibilities for the management of risk, combine to enhance the vulnerability and exposure of natural and human systems (IPCC 2014). Against this context, flood risk is considered to pose an inevitable and significant economic and social challenge to communities across the globe, necessitating progressive and holistic approaches to adaptive flood risk management.

New and innovative technologies and management systems have been identified as holding significant potential to help create resilient futures and could be highly costeffective (van Ree et al. 2011; Royas et al. 2013). Such adaptation efforts-it has been asserted-should prioritise measures that reduce the consequences of hazardous events, rather than trying to completely avoid their occurrence (Alfieri et al. 2016). The integration of adaptive 'solutions' requires careful consideration across traditional boundaries of practice. Recent work has identified how collaborative and interdisciplinary research has presented solutions to the manifold challenges of securing adaptation (Zevenbergen et al. 2013; Carter et al. 2015). For instance, given the high density of urban areas and increasing competition for land for transport, housing, employment, etc., there is a need to combine flood defence functions with other uses (van Ree et al. 2011). The use of green infrastructure-based approaches to enhance multifunctionality is also widely acknowledged as a 'win-win' solution to urban adaptation (Lindley et al. 2015).

However, despite the urgency of resilience agendas, the practical integration of necessary adaptive measures is frequently frustrated and often remains elusive. Points of resistance to flood adaptation initiatives range from political and administrative

Gina Cavan

G.Cavan@mmu.ac.uk

1 School of Science and the Environment, Manchester Metropolitan University, Chester Street, Manchester M1 5GD, UK 
impediments, to a lack of policy coordination, and cultural, social, and economic barriers (see White 2013; Connelly et al. 2015). Technical and engineering limitations pose a major challenge, providing a reminder of the importance of ensuring that 'solutions' are carefully integrated into societal contexts. It has been further asserted that resilience agendas can be divergent or even contradictory, in some instances creating maladaptive outcomes that might be counterproductive to the goals of adaptation (O'Hare et al. 2015).

Drawing upon empirical research that investigates the integration of flood adaptation measures in a variety of national contexts, the papers in this special issue propose a series of novel interpretations of adaptive responses to flood risk management. The papers examine the integration of adaptation to flooding from policy and practical perspectives and at various spatial scales. It unites divergent papers from various contexts to help isolate key themes that are critical to understanding the integration of flood adaptation measures. In particular, it includes papers across different geographical areas (Europe and Africa), encompassing issues from the developed and developing perspectives. It coalesces around recent and ongoing work that examines the integration of adaptive resilience and identifies opportunities for the development of innovative strategies of adaptation.

The issue provides a forum to identify both the forces that frame adaptation agendas, catalysing adaptive capacity and, in contrast, also those that hinder efforts to embed resilience. The papers consider how the urban fabric can be adapted from a practical and technical perspective, in addition to considering community, societal, and governance dimensions. Particular attention is paid to how the pursuit of flood adaptation agendas can expose competing rationalities and contested priorities for resilience. It further demonstrates how synergies between actors and alternative agendas may present opportunities for innovative and novel approaches to adaptive strategies.

This special issue consists of five articles. The first, by Herslund et al., presents a comprehensive multidimensional vulnerability assessment framework to understand and assess the impact of urban flooding. The vulnerability assessment framework recognises that numerous physical, institutional, attitudinal, and asset factors are interconnected and influence urban vulnerability across different spatial scales (e.g. from individual to community, plot to neighbourhood). Drawing upon a case study of Dar es Salaam, Tanzania, an interdisciplinary and mixed-method assessment demonstrates the application of the framework and illustrates the uneven distribution of vulnerability across the city, and its complexity in context, time, and scale. They conclude with some suggestions for implementing climate adaptation measures across different scales and discuss the processes by which these may be realised.

The second article, by Vedeld et al., examines the scalar dimensions of climate change adaptation in Saint Louis, Senegal, and in particular how this affects vulnerable sectors of society. Against the context of multilevel governance, the paper warns that adaptation cannot be addressed at any one discrete scale or by any single actor or stakeholder. Rather, the paper asserts that successful adaptation requires collaboration across politico-administrative boundaries and at multiple scales in order to reconcile competing policy agendas and tackle socio-spatial inequality and vulnerability. Drawing upon empirical insights, the paper suggests that there was a lack of investment in populations that are particularly vulnerable, undermining efforts to include communities as genuine partners in adaptation initiatives. The authors conclude that effective action necessitates "the meeting of demands and needs of all citizens_-including the poor who reside in the most risky and vulnerable areas."

The third article, by Gersonius et al., presents a pioneering example of a systematic analysis of the performance of the adaptive delta management (ADM) approach and 
associated current and proposed flood risk strategies in Dordrecht, the Netherlands. In the face of restrained public finances and a tendency for stakeholders to operate within relatively narrow disciplinary silos, the paper proposes that strategy development should ensure greater transparency for all concerned actors.

The fourth article, by Bracken et al., reviews how different types of borders-physical, conceptual and organisational-are treated within flood risk management, and how this influences decision-making practice. Using Q-methodology, community mapping, and focus groups on a case study on the River Tweed, the study demonstrates how physical and organisational borders are treated through practice, and how this frames efforts to achieve consensus in flood risk management decision-making.

The final article, by Mguni et al., focuses on the potential for green infrastructure (GI)based approaches to manage storm water in sub-Saharan cities, such as green roofs, rain gardens, and swales, collectively known as sustainable urban drainage (SUDS) or water sensitive urban design (WSUD) among other terms. Whilst there has been substantial investigation of such GI-based approaches in developed countries (e.g. USA, Europe, Australia), there are relatively few examples of implementation in developing countries. The review draws upon sustainable storm water management, urban planning, and governance literature to set out the strengths, weaknesses, opportunities, and threats, and assess the potential for adopting GI for storm water management in sub-Saharan cities. It calls for experimentation with GI-based SUDS at the local community scale which may perform as demonstration sites to understand and overcome the barriers outlined.

All in all, the special issue makes a point clear: there is a need to have a continuous focus on adaptive flood risk management measures, and to use this knowledge to handle future uncertainties.

Acknowledgments We gratefully acknowledge the authors for their support in producing manuscripts for this special issue, and the advice and time given by the invited referees of individual papers. We also thank Springer-NHAZ, for accepting our proposal for this thematic volume, in particular the Senior Editor, Dr. Petra van Steenbergen, the Editor-in-Chief, Professor Thomas Glade, Dr. Sridhar Bhavani, and Dr. Stefan van Dijl for their assistance and cooperation in producing the special issue.

\section{References}

Alfieri L, Feyen F, Di Baldassarre G (2016) Increasing flood risk under climate change: a pan-European assessment of the benefits of four adaptation strategies. Clim Change. doi:10.1007/s10584-016-1641-1

Carter JG, Cavan G, Connelly A, Guy S, Handley J, Kazmierczak A (2015) Climate change and the city: building capacity for urban adaptation. Prog Plan 95:1-66

Connelly A, Gabalda V, Garvin S, Hunter K, Kelly D, Lawson N, O'Hare P, White I (2015) Testing innovative technologies to manage flood risk. Proc ICE Water Manag 2(168):66-73

IPCC (2014) Summary for policymakers. In: Field CB, Barros VR, Dokken DJ, Mach KJ, Mastrandrea MD, Bilir TE, Chatterjee M, Ebi KL, Estrada YO, Genova RC, Girma B, Kissel ES, Levy AN, MacCracken S, Mastrandrea PR, White LL (eds) Climate change 2014: impacts, adaptation, and vulnerability. Part A: global and sectoral aspects. Contribution of working group II to the fifth assessment report of the intergovernmental panel on climate change. Cambridge University Press, Cambridge, pp 1-32

Lindley SJ, Gill SE, Cavan G, Kumelachew Y, Nebebe A, Woldegerima T, Kibassa D, Shemdoe R, Renner F, Buchta K, Abo-El-Wafa H, Printz A, Saa F, Coly A, Ndour NM, Feumba RA, Zogning MOM, Tonye E, Quedraogo Y, Samari SB, Sankara BT (2015) Green infrastructure for climate adaptation in African cities. In: Pauleit S, Coly A, Fohlmeister S, Gasparini P, Jorgensen G, Kabisch S, Kombe W, Lindley S, Simonis I, Yeshitela K (eds) Urban vulnerability and climate change in Africa-a multidisciplinary approach. Springer, Berlin

O'Hare P, White I, Connelly A (2015) Insurance as maladaptation: resilience and the 'business as usual' paradox. Environ Plan C 1-19. doi:10.1177/0263774X15602022 
Royas R, Fryan L, Watkiss P (2013) Climate change and river floods in the European Union: socioeconomic consequences and the costs and benefits of adaptation. Glob Environ Change 23(6):1737-1751

Van Ree CCDF, Van MA, Heilemann K, Morris MW, Royet P, Zevenbergen C (2011) FloodProBE: technologies for improved safety of the built environment in relation to flood events. Environ Sci Policy 14(7):874-883

White I (2013) The more we know, the more we don't know: reflections on a decade of planning, flood risk management and false precision. Plan Theory Pract 14(1):106-114

Zevenbergen C, van Herk S, Rijke J, Kabat P, Bloemen P, Ashley R, Speers A, Gersonius B, Veerbeek W (2013) Taming global flood disasters. Lessons learned from Dutch experience. Nat Hazards 65(3):1217-1225 